\title{
THE CLINICAL TEACHER
}

\section{Teaching clinical reasoning to medical students}

\begin{tabular}{|r|l|}
\hline Journal: & The Clinical Teacher \\
\hline Manuscript ID: & TCT-2012-0106.R1 \\
\hline Manuscript Type: & Original manuscript \\
\hline Keywords: & $\begin{array}{l}\text { Clinical \& Procedural Skills Training, Clinical Education, Communication } \\
\text { skills, Community based education, Instructional Materials/Methods, } \\
\text { Curriculum Development/Evaluation }\end{array}$ \\
\hline
\end{tabular}

\section{SCHOLARONE}

Manuscripts

'This is a version of the following article: Gay, S and Bartlett, M and McKinley, R (2013) Teaching clinical reasoning to medical students. Clinical Teacher, 10 (5). 308 - 312, which has been published in final form at [http://onlinelibrary.wiley.com/doi/10.1111/tct.12043/full]. This article may be used for non-commercial purposes in accordance With Wiley Terms and Conditions for self-archiving'. 


\section{Abstract}

\section{Background}

***** Medical School's new curriculum includes a five week course to extend students' consultation skills beyond those required for the inductive method of clinical decision making.

\section{Context}

Clinical reasoning is known to have implications for patient safety and this course aims to contribute to the development of students' clinical reasoning skills.

The course takes place in the fourth year and is set into the students' clinical placements, giving them opportunities to practice and therefore quickly embed their learning.

\section{Innovation}

This report describes the clinical reasoning based classroom and community teaching.

\section{Implications}

Early evaluation suggests that the students value the course and benefit from it. 


\section{Teaching clinical reasoning to medical students}

\section{Background}

As part of an innovative new curriculum, fourth year students at ${ }^{* * * *}$ Medical School further develop their consultation skills, specifically including clinical reasoning skills, in a course delivered in five 4 day blocks which are embedded in eight week long secondary care placements throughout the year. The overall consultation skills curriculum is spiral; this course builds on communication skills (year 1), clinical interviewing and examination skills (years 2 and 3 ), and teaches skills which are essential in all clinical settings.

\section{Context}

During the fourth year, we aim to move the students from being collectors and reporters of information to being interpreters of information who can make diagnoses and managers who can construct appropriate management plans and achieve shared decision-making with patients. ${ }^{1}$ This involves actively teaching clinical reasoning and clinical management skills and further developing their communication skills, with the expectation that we improve both decision making and patient safety. ${ }^{2}$

\section{Innovation}

The new course started in the 2010-11 academic year. Each of the five blocks consists of one day of classroom teaching delivered by experienced general practitioners who have been trained to deliver this programme. Students then spend three days practicing their new skills with patients in general practices.

The teaching material is varied, and consists of trigger materials, described later, which have been selected to stimulate and promote learning. Wherever possible, cases drawn from the authors' clinical practice are used as frameworks for learning thus providing authentic clinical material relevant to current medical practice. In addition, students bring general practice and hospital cases to discuss with the group in order to explore their own decision making processes.

The classroom tutors are supported by comprehensive teaching notes, which include background theory and evidence, for example excerpts from relevant journal articles and clinical guidelines, and suggestions for further reading. Each tutor works with a group of eight to ten students.

The students' learning on the course is assessed in both the written examinations and the OSCEs. 
The classroom days focus on five areas in turn (summarised in box 1):

\section{- Week 1: Making a Diagnosis and Appropriate Information Gathering}

We consider the process of making a diagnosis and the need to make rational and conscious choices about the information which must be gained from history-taking, examination and investigation. ${ }^{3}$ We look at three different diagnostic processes:

- Pattern recognition;

- Induction or "Exhaustion"(the traditional 'prototypic' process of full history and full examination before considering a diagnosis) ${ }^{4}$;

- Hypothetico-deductive method ${ }^{5}$ in which, from first contact with the patient, taking into account prior information and the context of the consultation, hypotheses are constructed and tested through appropriate information gathering. Hypotheses are re-visited as information is gathered and conscious decisions made as to whether they are upheld or refuted.

We introduce the concepts of analytical and non-analytical processes (table 1) and dual process theory (figure 1 and box 2) to give students an awareness of the tools they might use in consultations, how the tools inter-relate, and a vocabulary with which to discuss them.

\section{- Week 2: Biases and Error in Medical Practice}

We introduce the concept of metacognition ${ }^{6,7}$ (thinking about thinking, and the active control of one's thinking process). We use a wide variety of trigger materials to promote thought and discussion about sources of error in clinical practice:

- Optical illusions to show that error is part of our cerebral 'hard wiring'.

- X-rays to demonstrate search satisfaction bias and how metacognition incorporating analytical thinking reduces the risk of cognitive errors. ${ }^{7}$

- Clinical quizzes to illustrate pattern recognition as a diagnostic tool, and also the importance and pitfalls of illness scripts. ${ }^{8}$

- Non-clinical quizzes to demonstrate a range of biases, the cognitive miser function (the "tendency to limit cognitive effort in reasoning") 9 and the effects of time pressure and distraction on the ability to process complex information. 
- Critical incident reviews to promote discussion of Reason's classification of cognitive, skill based and rule based error. ${ }^{10}$ By heightening students' awareness of high risk situations and decisions, we aim to increase their ability to develop their own cognitive forcing strategies $^{7}$ (strategies to counter specific cognitive errors).

- Bayes Theorem ${ }^{11}$ and conditional probability are demonstrated using clinical cases to emphasise the importance of logically re-evaluating hypotheses in the light of new information.

- Clinical cases are used to analyse errors and identify their origins in different biases, as well as the strengths and weaknesses of heuristics.

We explore the details of the Dual Process model, ${ }^{12}$ which demonstrates how the two decision making processes might interact with each other, and discuss where metacognition fits within this model (the overriding of one system by the other, and in calibration before the final decision is made). We also use the model to discuss human and system factors which contribute to errors in clinical practice, with reference to the trigger materials used earlier in the session.

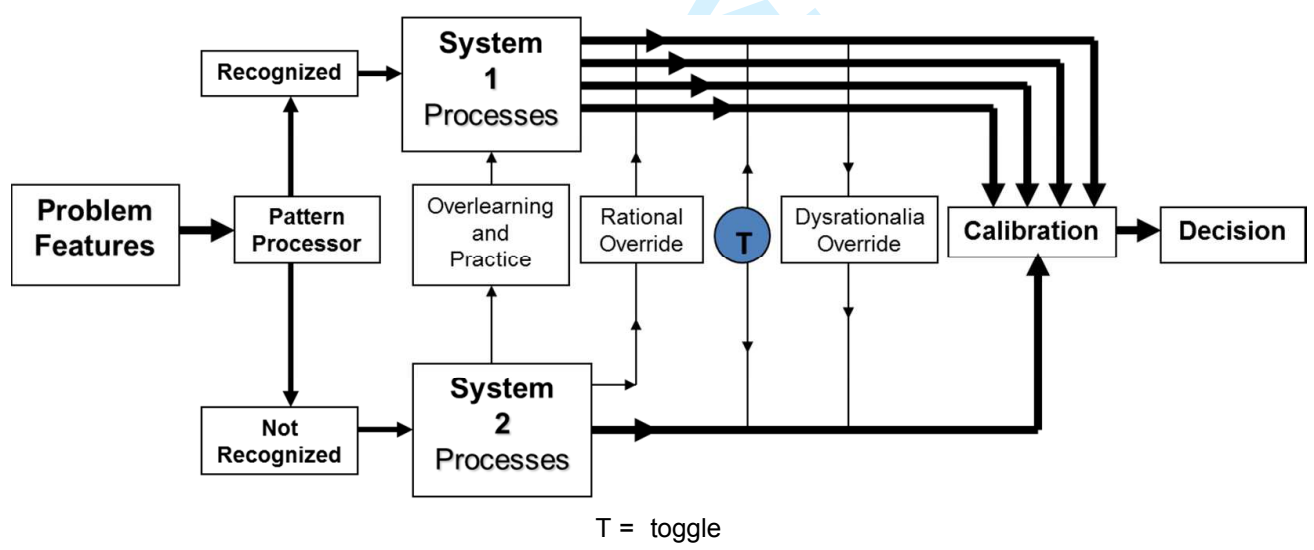

Figure 1: Dual Process diagram included with permission from Professor P. Croskerry

\section{- Week 3: Information Management}

We use clinical vignettes to develop students' ability to undertake effective searches for valid evidence based information within the consultation. Such information may be about or for the patient, or for the doctor. We teach that effective use of information involves clinical reasoning to appraise both 
information sources and the evidence available. Students learn specific communication skills relating to the use of information within the consultation, such as signposting, interpreting clinical information for patients and how to share relevant information with other clinicians. They also learn how to incorporate information into their consultations in line with Sackett's definition of Evidence Based Medicine: ${ }^{13}$

"...integrating individual clinical expertise with the best available external clinical evidence..."

We look critically at referral and discharge letters and show how the application of effective clinical reasoning can make both more effective. Clinical cases are used to illustrate the principles of information governance.

\section{- Week 4: Effective Management}

The focus is on achieving shared understandings with patients, and using clinical reasoning to construct management plans which account for patients' specific needs and preferences, and the constraints which may influence the acceptability of treatment. Simulated patients are used to practice the reasoning and communication skills involved in negotiating with and empathising with the patient.

We also consider the need to build 'safety nets' into consultations, and the reasoning involved in making these effective and appropriate. ${ }^{14}$

\section{- Week 5: Maximising Adherence}

We look at shared decision making, assessing adherence, talking with patients about risk and using a variety of patient decision aids.

We also introduce the concept of 'minimally disruptive medicine' and the importance of tailoring treatment to individuals to increase their ability to adhere to treatment regimens ${ }^{15}$ thus improving outcomes. Students practice these skills with, and receive feedback on these skills from, simulated patients.

\section{Implications}

Student feedback has been very good, both in questionnaire surveys and in focus groups. In the first year of implementation $89 \%$ of students reported that they understood the material covered (which we consider to be excellent given the 
complexity of much of it), $76 \%$ understood how it applied to their general practice placements and $64 \%$ had tried to apply these skills while in general practice.

Overall, $86 \%$ of students felt that the classroom material was relevant to them as $4^{\text {th }}$ year medical students and they were particularly enthusiastic about the hypotheticodeductive method and its use in case discussion.

The students' comments afford additional insights into the perceived value of the programme to individuals. The following comments are typical examples:

“...helped me think about diagnosing conditions in a more logical and useful way..."

“...informative and wholly applicable to my future practice."

“...bridging the gap between taking a history as a student and thinking like a doctor..."

Further evaluation using a pre and post programme diagnostic thinking inventory ${ }^{16}$ is currently in progress.

We consider that while we have achieved much, challenges remain. In particular, there is a need for further faculty development with regard to clinical reasoning both in primary and secondary care so that learning can be reinforced in all clinical settings. We have started to address this issue through our clinical teacher development programme and by close consultation with our secondary care colleagues.

We consider this to be a highly innovative educational programme with a structure, process and content which allows undergraduate students to assimilate complex material presented at a level that is appropriate to their stage of learning. Importantly, it directly links current clinical reasoning theory with clinical practice. We believe that the course addresses cognitive aspects of patient safety alongside effective clinical education ${ }^{2}$ in an interesting, engaging and constructive way at a time when the students have some competence in clinical skills but need to develop safe, effective, personal clinical practice. 


\section{References}

1. Pangaro, L.N. (1999) A new vocabulary and other innovations for improving descriptive in-training evaluations, Acad Med 1999;74:1203-1207.

2. Balla J, Heneghan C, Thompson M, Balla M. Clinical decision making in a high risk primary care environment. BMJ Open 2012;2:e000414.doi:10.1136/bmjopen-2011-000414

3. Hoffbrand BI. Away with the System Review: a plea for Parsimony. BMJ 1989;298:817-819.

4. Sackett DL, Haynes RB, Guyatt GH, Tugwell P. Clinical epidemiology: A basic science for clinical medicine, $2^{\text {nd }}$ edition. Boston: Little, Brown and Co. 1991.

5. Elstein AS, Shulman LS, Sprafka SA. Medical problem solving: an analysis of clinical reasoning. Cambridge, MA: Harvard University Press; 1978.

6. Epstein R. Mindful practice. JAMA 1999;282(9):833-839.

7. Croskerry $P$. The importance of cognitive errors in diagnosis and strategies to minimise them. Acad Med 2003;78:775-780.

8. Schmidt HG, Norman GR, Boshuizen HP. A cognitive perspective on medical expertise: theory and implication. Acad Med 1990;65:611-21.

9. Croskerry P. Context is everything or how could I have been that stupid? Healthc Q 2009;12 Spec No Patient:e171-6.

10. Reason J. The Human Contribution: unsafe acts, accidents and heroic recoveries. Farnham: Ashgate Publishing Limited, 2008.

11. Bayes, T. An essay towards solving a problem in the doctrine of chances. Phil Trans 1763;53:370-418.

12. Croskerry P. A universal model of diagnostic reasoning. Acad Med 2009;84:1022-8.

13. Sackett DL, Rosenberg WMC, Gray JAM, Haynes RB, Richardson WS: Evidence based medicine: what it is and what it isn't. BMJ 1996;312:71-2.

14. Almond S, Mant D, Thompson M. Diagnostic Safety Netting. Br J Gen Pract 2009;59:872-874.

15. May C, Montori VM, Mair FS. We need minimally disruptive medicine. BMJ 2009;339:b2803.

16. Bordage G, Grant J, Marsden P. Quantitative assessment of diagnostic ability. Med Educ 1990;24:413-425.

17. Croskerry P, Nimmo G.R. Better clinical decision making and reducing diagnostic error. J R Coll Physicians Edinb 2011;41:155-162. 
Box 1. Clinical reasoning - classroom teaching themes

- Making a diagnosis and appropriate information gathering

- Biases and error in medical practice

- Information management

- Effective management

- Maximising adherence 
Rational override: switch from analytical processing (System 2) to non-analytical processing (System 1).

Dysrationalia override: switch from non-analytical processing (System 1) to analytical processing (System 2). The trigger for the switch may not be consciously recognised.

Toggle: represents multiple oscillations between systems $1+2$ which help "to produce a well-calibrated response".

Calibration: internal review of potential accuracy of process endpoint in relation to any prior experience.

Box 2: Explanation of terms used in the dual process diagram 


\begin{tabular}{|c|c|}
\hline Non-analytical & Analytical \\
\hline System 1 & System 2 \\
fast & slow \\
subconscious & conscious \\
low effort & high effort \\
involuntary & voluntary \\
\hline
\end{tabular}

Table 1: Some features of analytical and non-analytical processes 